\title{
Evaluation of Free Available Chlorine of Sodium Hypochlorite When Admixed with $0.2 \%$ Chitosan: A Preliminary Study
}

\author{
Prashanth Bytarahosalli Rajachar ${ }^{1}$, Mythreyee S Vidhya ${ }^{2}$, Rupali Karale ${ }^{3}$, Vinay Kumar Govindaraju ${ }^{4}$, Nithin K Shetty ${ }^{5}$
}

\begin{abstract}
Aim and objective: The aim of the study was to evaluate the changes in free available chlorine (FAC) when $6 \%$ sodium hypochlorite (NaOCl) is admixed with irrigants $17 \%$ ethylenediaminetetraacetic acid (EDTA), $2 \%$ chlorhexidine (CHX), and $0.2 \%$ chitosan in varying proportions of 90:10, 80:20, and 50:50.

Materials and methods: The $25 \mathrm{~mL}$ aliquots of $6 \% \mathrm{NaOCl}$ were admixed in varying proportions of 90:10, 80:20, and 50:50 with secondary irrigation solutions: (a) $17 \%$ EDTA, (b) $2 \%$ CHX, (c) $0.2 \%$ chitosan. lodometric titration was done to evaluate the change in FAC.

Statistical analysis used: Kruskal-Wallis and Mann-Whitney tests.

Results: On titration, the mean FAC value of $\mathrm{NaOCl}$ at baseline was $1.99 \mathrm{~g} \%$. On mixing $\mathrm{NaOCl}$ with EDTA, the FAC decreased in all the three proportions and the values were $0.17 \mathrm{~g} \%, 0.17 \mathrm{~g} \%$, and $0.06 \mathrm{~g} \%$ at 90:10, 80:20, and 50:50 ratios, respectively. pH obtained was 9.55 at 50:50 ratio. On mixing $\mathrm{NaOCl}$ with $\mathrm{CHX}$, FAC reduced and the values were $1.84 \mathrm{~g} \%, 1.72 \mathrm{~g} \%$, and $0.27 \mathrm{~g} \%$ at 90:10, 80:20, and 50:50 ratios, respectively. $\mathrm{pH}$ obtained was 10.87 at 50:50 ratio. On mixing $\mathrm{NaOCl}$ and chitosan, the FAC remained unaltered in all the three proportions and the values were $1.64 \mathrm{~g} \%, 1.51 \mathrm{~g} \%$, and $1.63 \mathrm{~g} \%$ at 90:10, 80:20, and 50:50 ratios, respectively. pH obtained was 11 at 50:50 ratio.

Conclusion: Combination of $\mathrm{NaOCl}$ and chitosan did not lead to a reduction in $\mathrm{FAC}$ and the $\mathrm{pH}$ of the solution remained unaltered, suggesting that tissue-dissolving property of $\mathrm{NaOCl}$ might be preserved.

Clinical significance: The combination of chitosan with $\mathrm{NaOCl}$ is advantageous in two ways. Firstly, FAC remained unaltered and the $\mathrm{pH}$ of the solution was also maintained at 11.05 indicating that the tissue-dissolving property of $\mathrm{NaOCl}$ prevailed. Secondly, chitosan is known for its chelating property and is effective in smear layer removal. With further in vivo and in vitro studies, a combination of chitosan and $\mathrm{NaOCl}$ can be proposed as a novel irrigant. Keywords: Chlorhexidine, Chitosan, Ethylenediaminetetraacetic acid, Free available chlorine, lodometric titration, Sodium hypochlorite. The Journal of Contemporary Dental Practice (2021): 10.5005/jp-journals-10024-3207
\end{abstract}

\section{INTRODUCTION}

Sodium hypochlorite $(\mathrm{NaOCl})$ has a better tissue-dissolving potential and antibacterial properties, so it is one of the most widely used irrigants. ${ }^{1} \mathrm{pH}$ of the $\mathrm{NaOCl}$ solution determines the active form, i.e., hypochlorous acid $(\mathrm{HOCl})$ or hypochlorite ion $\left(\mathrm{OCl}^{-}\right)$that is available, as a whole account for the free available chlorine (FAC) content of $\mathrm{NaOCl}$. The $\mathrm{FAC}$ of the $\mathrm{NaOCl}$ is responsible for protein degradation action and antibacterial property. ${ }^{2}$ The available chlorine of hypochlorite solutions appears to influence the caustic potential. Despite the good tissue-dissolving property of $\mathrm{NaOCl}$, it is ineffective against certain microorganisms and smear layer. Ethylenediaminetetraacetic acid (EDTA) is a chelating agent which is effective in removing smear layer from root canals. ${ }^{3}$ No single solution is able to fulfill these actions completely; therefore, their combination is required. Hence, the suggested clinical protocol is the usage of irrigants such as EDTA and chlorhexidine (CHX) in conjunction with $\mathrm{NaOCl} .{ }^{4}$ Unfortunately, such a combination of irrigants may lead to a decrease in the efficacy of $\mathrm{NaOCl}$ and also lead to the formation of precipitate that is considered to be toxic. Previous studies have shown that the FAC drastically reduced when EDTA was used in conjunction with $\mathrm{NaOCl}$. 2,5

The use of $\mathrm{CHX}$ with $\mathrm{NaOCl}$ has been advocated to enhance the antimicrobial properties. But the combination of $\mathrm{CHX}$ with $\mathrm{NaOCl}$ leads to the formation of a colored undesired precipitate and causes a drop in FAC of the solution. ${ }^{5}$

Over the past years, a new biopolymer, chitosan derived by the partial deacetylation of chitin obtained from crustacean
${ }^{1-4}$ Department of Conservative Dentistry and Endodontics, KLE Society's Institute of Dental Sciences, Bengaluru, Karnataka, India

${ }^{5}$ Faculty of Dental Science, MS Ramaiah University of Applied Science, Bengaluru, Karnataka, India

Corresponding Author: Prashanth Bytarahosalli Rajachar, Department of Conservative Dentistry and Endodontics, KLE Society's Institute of Dental Sciences, Bengaluru, Karnataka, India, Phone: + 919449638113 , email: drprashanthraj@gmail.com

How to cite this article: Rajachar PB, Vidhya MS, Karale R, et al. Evaluation of Free Available Chlorine of Sodium Hypochlorite When Admixed with $0.2 \%$ Chitosan: A Preliminary Study. J Contemp Dent Pract 2021;22(10):1171-1174.

Source of support: Nil

Conflict of interest: None

shells has been introduced for root canal irrigation..$^{6,7}$ It has been reported to remove the smear layer and inhibit bacterial recolonization when used as a final irrigant during disinfection of the canal system. ${ }^{8}$

The effect of some secondary irrigants such as EDTA and CHX on $\mathrm{FAC}$ of $\mathrm{NaOCl}$ has been investigated. Interaction of $\mathrm{NaOCl}$ and chitosan on the FAC remains unknown.

On that account, a preliminary study was carried out with the aim to evaluate the changes in $\mathrm{FAC}$ when $6 \% \mathrm{NaOCl}$ is admixed with irrigants $17 \%$ EDTA, $2 \% \mathrm{CHX}$, and $0.2 \%$ chitosan.

(c) The Author(s). 2021 Open Access This article is distributed under the terms of the Creative Commons Attribution 4.0 International License (https://creativecommons. org/licenses/by-nc/4.0/), which permits unrestricted use, distribution, and non-commercial reproduction in any medium, provided you give appropriate credit to the original author(s) and the source, provide a link to the Creative Commons license, and indicate if changes were made. The Creative Commons Public Domain Dedication waiver (http://creativecommons.org/publicdomain/zero/1.0/) applies to the data made available in this article, unless otherwise stated. 
Hence, the aim of our study was to evaluate the changes in FAC when $6 \% \mathrm{NaOCl}$ is admixed with irrigants $17 \% \mathrm{EDTA}, 2 \% \mathrm{CHX}$, and $0.2 \%$ chitosan in varying proportions of $90: 10,80: 20$, and 50:50.

\section{Materials and Methods}

The study was conducted at the Department of Biochemistry, KLE Society's Institute of Dental Sciences, Bengaluru, Karnataka, India.

The primary solution used was $6 \% \mathrm{NaOCl}$ (Karnataka Fine Chem, Bengaluru).

The secondary solutions were as follows:

- $\quad$ 17\% EDTA (Dent Wash, Prime Dental)

- $2 \%$ CHX (Asep RC, Anabond Stedman)

- $0.2 \%$ Chitosan (Chitorigant, Everest Biotech)

\section{Group Distribution (Total Sample Size $N=3$ Titrations in Each Group)}

Group I: $6 \% \mathrm{NaOCl}+$ distilled water

Group II: $6 \% \mathrm{NaOCl}+17 \%$ EDTA

Group III: $6 \% \mathrm{NaOCI}+2 \% \mathrm{CHX}$

Group IV: $6 \% \mathrm{NaOCI}+0.2 \%$ chitosan

The primary solution and secondary solution were admixed to make up $25 \mathrm{~mL}$ aliquots of different proportions in iodine flask. Therefore, the groups were again divided into subgroups $(n=3)$ based on the different proportions and their compositions as follows:

- $90: 10,22.5 \mathrm{~mL} 6 \% \mathrm{NaOCl}+2.5 \mathrm{~mL}$ secondary solution

- $80: 20,20 \mathrm{~mL} 6 \% \mathrm{NaOCl}+5 \mathrm{~mL}$ secondary solution

- $50: 50,12.5 \mathrm{~mL} 6 \% \mathrm{NaOCl}+12.5 \mathrm{~mL}$ secondary solution

The test sample solutions were made according to the previous study by Krishnan et al. ${ }^{2}$ Baseline FAC of the primary solution was first established from a mean of three iodometric titrations independently. Then immediately after mixing, FAC content of the mixtures was established. A $25 \mathrm{~mL}$ fraction of experimental test group solution in all three different ratios was assessed by iodometric titration and the average of three titrations was considered.

Steps in lodometric titration were as follows:

- $0.1 \mathrm{~N}$ Sodium thiosulphate was prepared by dissolving $25 \mathrm{~g}$ of sodium thiosulphate in $1 \mathrm{~L}$ of distilled water.

$1 \mathrm{~mL}$ of $0.1 \mathrm{~N}$ sodium thiosulphate $=3.54 \mathrm{~g}$ of active chlorine.

- In an iodine flask, the corresponding proportion of $\mathrm{NaOCl}$ and the secondary solution, $1 \mathrm{~g}$ of potassium iodide, and $5 \mathrm{~mL}$ of diluted sulfuric acid were added. A stopper was placed and stored in a dark place for 10 minute.

- Titration was carried out against $0.1 \mathrm{~N}$ sodium thiosulphate.

During iodometric titration, a starch solution was used as an indicator since it can absorb the iodine that was released. This absorption caused the solution to change its color, from dark blue to a colorless state when titrated with a standardized thiosulfate solution. This indicated the end point of the titration. The amount of lodine liberated is directly equal to the amount of FAC.

pH estimation: A digital $\mathrm{pH}$ meter (Systronics) was used to record the $\mathrm{pH}$ of the experimental solutions. Test solutions were admixed in 50:50 concentration and the $\mathrm{pH}$ was estimated soon after mixing before the start of iodometric titration.

\section{Data Analysis}

SPSS 22.0 (SPSS Inc, Armonk, New York) software was used for the statistical analysis. A Kruskal-Wallis test was employed to measure the variations in $\mathrm{FAC}$ between $\mathrm{NaOCl}$ group with other groups and Mann-Whitney test was used to measure the intragroup variations in FAC. The level of significance was $p<0.05$.

\section{Results}

The baseline FAC of the primary solution ( $\mathrm{NaOCl}$ ) of $1.99 \mathrm{~g} \%$ was obtained. There was a statistically significant decrease in FAC when $\mathrm{NaOCl}$ was admixed with the secondary solutions even at varying proportions.

\section{Group I}

When $\mathrm{NaOCl}$ was diluted with distilled water, the mean FAC at 90:10 ratio was $1.91 \mathrm{~g} \%$, at 80:20, $1.81 \mathrm{~g} \%$; and at 50:50, $1.52 \mathrm{~g} \%$.

\section{Group II}

The mean FAC obtained when $\mathrm{NaOCl}$ was admixed with EDTA at 90:10 ratio was $0.17 \mathrm{~g} \%$, at 80:20, $0.17 \mathrm{~g} \%$; and 50:50, $0.06 \mathrm{~g} \%$.

There was a drastic drop in FAC at all the different proportions immediately after mixing.

\section{Group III}

On combining $\mathrm{NaOCl}$ with $\mathrm{CHX}$, the mean $\mathrm{FAC}$ values obtained at 90:10 ratio was $1.84 \mathrm{~g} \%$; at 80:20, $1.72 \mathrm{~g} \%$; and at 50:50, $0.27 \mathrm{~g} \%$.

The 50:50 proportion of $\mathrm{CHX}$ with $\mathrm{NaOCl}$ resulted in a drastic drop in FAC.

\section{Group IV}

The mean FAC when $\mathrm{NaOCl}$ and chitosan were combined at 90:10 ratio was $1.64 \mathrm{~g} \%$; at $80: 20,1.51 \mathrm{~g} \%$; and at 50:50, $1.63 \mathrm{~g} \%$. The loss of FAC remained the same in the subgroups and was close to the values obtained when $\mathrm{NaOCl}$ was diluted with distilled water.

In our current experiment, the $\mathrm{pH}$ of the test solutions at 50:50 concentration was measured to simulate the clinical method of 50:50 admixtures of irrigants. This was measured using a digital $\mathrm{pH}$ meter (Systronics) and the values recorded were as follows:

Group I: pH 11.27

Group II: pH 9.55

Group III: pH 10.87

Group IV: pH 11.05

\section{Discussion}

FAC is defined as a measurement of oxidizing capacity. Sum of the $\mathrm{HOCl}$ and $\mathrm{OCl}^{-}$concentrations in the $\mathrm{NaOCl}$ solution constitutes the FAC. $\mathrm{HOCl}$, a stronger oxidant than the $\left(\mathrm{OCl}^{-}\right)$, is accountable for the strong chlorinating and oxidizing action on tissue and microorganism. ${ }^{8,9}$

In spite of the fact that $\mathrm{NaOCl}$ appears to be the most desirable single endodontic irrigant, it cannot dissolve inorganic dentin particles and is not efficacious in smear layer removal. ${ }^{10}$ Therefore, the use of other irrigants in conjunction with $\mathrm{NaOCl}$ has been proposed, but such a combination leads to a reduction in FAC.

The effect of dilution and a chemical reaction between the irrigants could be the reason for a reduction in FAC in these admixtures. ${ }^{2,11}$ For this reason, FAC of independent $6 \% \mathrm{NaOCl}$ solution was measured prior to mixing with secondary solutions 
and then the effect of dilution of $\mathrm{NaOCl}$ with distilled water was recorded (Fig. 2A). Thus, any further loss in FAC of these admixtures would probably indicates a chemical reaction occurred between the primary and secondary irrigant solutions. , $^{, 11}$
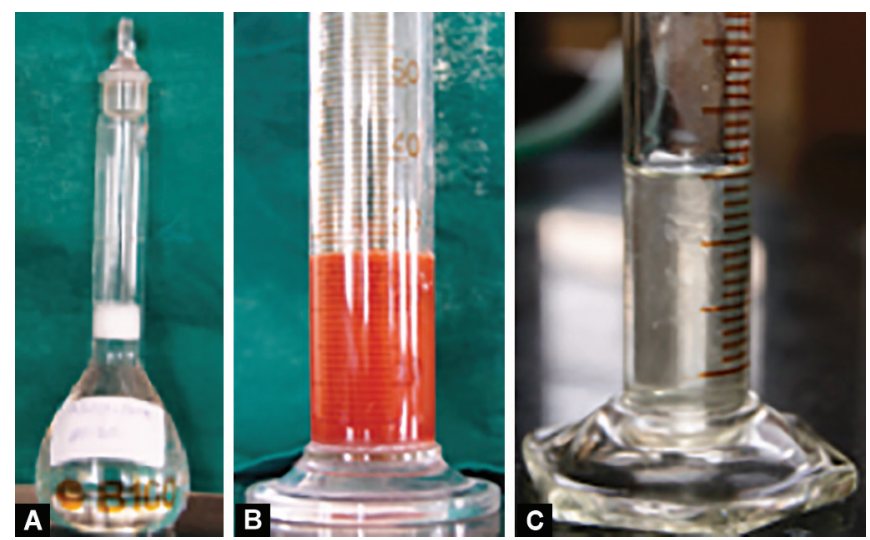

Figs $1 \mathrm{~A}$ to $\mathrm{C}$ : (A) Showing a rapid gas formation when 17\% EDTA was admixed with $6 \% \mathrm{NaOCl}$ in 80:20 proportion; (B) Depicting orange-red precipitate formation when $2 \% \mathrm{CHX}$ was mixed with $6 \% \mathrm{NaOCl}$ in $50: 50$ proportion; (C) Showing the initial turbidity observed in the solution when $0.2 \%$ chitosan was mixed with $6 \% \mathrm{NaOCl}$ in $50: 50$ proportion
The rate of loss of available chlorine when $\mathrm{NaOCl}$ is mixed with EDTA and CHX is shown to vary according to the different proportions of the admixture. Therefore, based on the experimental criteria followed in the previous research by Krishnan et al., the different proportions of 90:10, 80:20, and 50:50 were chosen in the current study. ${ }^{2}$

When $\mathrm{NaOCl}$ was combined with EDTA, an exothermic reaction took place with a rapid gas formation (Fig. 1A). The results of the present study showed that there was a rapid and dramatic decrease in FAC in all the experimental proportions (Fig. 2B). The results obtained are congruent with the previous research by Krishnan et al. and Clarkson et al. ${ }^{2,12}$ Due to this rapid loss in FAC, these irrigants must not be used concomitantly. ${ }^{12}$

The combined use of $\mathrm{NaOCl}$ and $\mathrm{CHX}$ has been advocated to enhance their antimicrobial properties and is shown to provide substantivity. ${ }^{4}$ When these two irrigants were mixed, it resulted in an orange-red precipitate (Fig. 1B) as observed, Zehnder. RossiFedele et al. have identified the precipitate as parachloroaniline, whereas Orhan et al. suggested that the obtained precipitate is chlorophenylurea based on spectroscopy studies. ${ }^{5,13}$ Concentration and admixture ratio had an effect on FAC and resulted in a significant drop in FAC at 50:50 proportion (Fig. 2C). The combination of $\mathrm{NaOC}$ and $\mathrm{CHX}$ caused color changes and the formation of a neutral and insoluble precipitate, which may interfere with the seal of the root
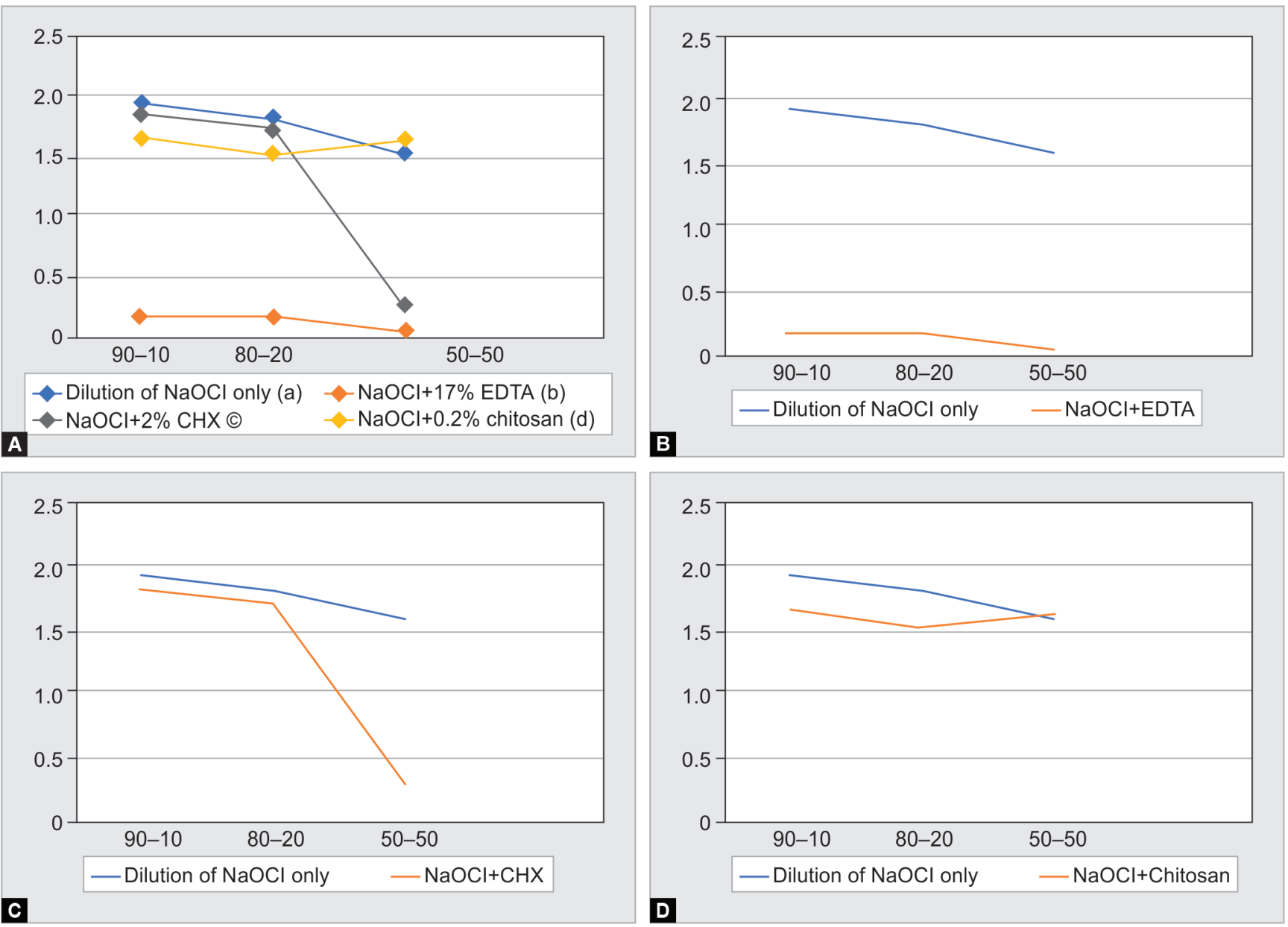

Figs 2A to D: (A) Mean FAC of all the groups; (B) Mean FAC of NaOCl with EDTA; (C) Mean FAC of NaOCl with NaOCl with CHX; (D) Mean FAC of $\mathrm{NaOCl}$ with chitosan 
filling. Therefore, drying the canal with paper points before the final $\mathrm{CHX}$ rinse is suggested. ${ }^{14}$

Chitosan, a nontoxic cationic biopolymer, is obtained by alkaline deacetylation from chitin. ${ }^{6,7}$ Chitosan used in endodontics presents with the advantage of biocompatibility, chelating capacity, and also antimicrobial effects against a broad range of gram-positive and gram-negative bacteria as well as fungi. ${ }^{15}$ The rate of active chlorine loss that occurs when solutions of $\mathrm{NaOCl}$ and chitosan are mixed and the effect of different proportions of the admixture on active chlorine have not previously been reported. When chitosan was admixed with $\mathrm{NaOCl}$, initial white turbidity was observed in the solution that disappeared soon (Fig. 1C). The mean difference in FAC after mixing chitosan was close to FAC obtained when $\mathrm{NaOCl}$ was mixed with distilled water (Fig. 2D). Reduction in FAC was not statistically significant in all three different proportions. Chitosan is a chelating agent with actions similar to EDTA. There was no undesirable precipitate formation with this admixture unlike that observed in a combination with $\mathrm{CHX}$.

The properties of $\mathrm{NaOCl}$ are dependent on the $\mathrm{pH}$ of the solution. The $\mathrm{pH}$ varies significantly and ranges between 10.9 and 12.0. At $\mathrm{pH}$ values of 9 and above, $\mathrm{OCl}^{-}$predominates and tissue dissolution is maximized. $\mathrm{HOCl}$ is mostly present at the neutral $\mathrm{pH}$ and antibacterial ability is maximized, ${ }^{12}$ whereas $\mathrm{pH}$ of the primary solution (group I) was 11.27. In combination with EDTA (group II) and CHX (group III), the $\mathrm{pH}$ of the solution dropped to 9.55 and 10.87 , respectively, which results in reduced efficacy of $\mathrm{NaOCl}$. In contrast, with $0.2 \%$ chitosan, the $\mathrm{pH}$ of the solution was 11.05 indicating that the $\mathrm{pH}$ of $\mathrm{NaOCl}$ was not altered. This suggests that the tissue-dissolving property will prevail when $\mathrm{NaOCl}$ is used in conjunction with chitosan. Also, this combination might be advantageous than EDTA as properties of $\mathrm{NaOCl}$ remain unaltered because the $\mathrm{FAC}$ remained constant. Additionally, chitosan helps in effective smear layer removal. Further investigations can be carried out to evaluate the chemical reaction between $\mathrm{NaOCl}$ and chitosan and the antibacterial efficacy of this admixture and evaluation of change in $\mathrm{pH}$ with different proportions.

Within the limitations of the present study, it can be concluded that:

- $\mathrm{NaOCl}$ solutions when admixed with EDTA led to a marked reduction in FAC, thus limiting the combined usage of both irrigants simultaneously.

- At 50:50 ratio, CHX showed a marked reduction in FAC. Orange-red precipitate formation was observed.

- Combination with chitosan did not cause a significant drop in FAC and $\mathrm{pH}$ of $\mathrm{NaOCl}$ was unaltered.

\section{Limitations of the Study}

This is a preliminary study; thus, the sample size was less. Quantitative methods such as fourier-transform infrared spectroscopy (FTIR) can be used to accurately measure the chlorine levels. $\mathrm{pH}$ at different concentrations could have been evaluated.

\section{Clinical Significance}

The combination of chitosan with $\mathrm{NaOCl}$ is advantageous in two ways. Firstly, FAC remained unaltered and the $\mathrm{pH}$ of the solution was also maintained at 11.05 indicating that the tissue-dissolving property of $\mathrm{NaOCl}$ prevailed. Secondly, chitosan is known for its chelating property and is effective in smear layer removal. With further in vivo and in vitro studies, the combination of chitosan and $\mathrm{NaOCl}$ can be proposed as a novel irrigant.

\section{References}

1. Gonçalves LS, Rodrigues RC, Junior CV, et al. The effect of sodium hypochlorite and chlorhexidine as irrigant solutions for root canal disinfection: a systematic review of clinical trials. J Endod 2016;42(4):527-532. DOI: 10.1016/j.joen.2015.12.021.

2. Krishnan U, Saji S, Clarkson R, et al. Free active chlorine in sodium hypochlorite solutions admixed with Octenidine, SmearOFF, Chlorhexidine, and EDTA. J Endod 2017;43(8):1354-1359. DOI: 10.1016/j.joen.2017.03.034.

3. Zehnder $M$, Schmidlin $P$, Sener $B$, et al. Chelation in root canal therapy reconsidered. J Endod 2005;31(11):817-820. DOI: 10.1097/01. don.0000158233.59316.fe.

4. Zehnder M. Root canal irrigants. J Endod 2006;32(5):389-398. DOI: 10.1016/j.joen.2005.09.014.

5. Rossi-Fedele G, Doğramaci EJ, Guastalli AR, et al. Antagonistic Interactions between Sodium Hypochlorite, Chlorhexidine, EDTA, and Citric Acid. J Endod 2012;38(4):426-431. DOI: 10.1016/ j.joen.2012.01.006.

6. Silva PV, Guedes DF, Nakadi FV, et al. Chitosan: a new solution for removal of smear layer after root canal instrumentation. Int Endod J 2013;46(4):332-338. DOI: 10.1111/j.1365-2591.2012.02119.x.

7. Darrag AM. Effectiveness of different final irrigation solutions on smear layer removal in intraradicular dentin. Tanta Dent J 2014;11(2):93-99. DOI: 10.1016/j.tdj.2014.06.002.

8. Geethapriya N, Subbiya A, Padmavathy K, et al. Effect of chitosan-ethylenediamine tetraacetic acid on Enterococcus faecalis dentinal biofilm and smear layer removal. J Conserv Dent 2016;19(5):472-477. DOI: 10.4103/0972-0707.190022.

9. Estrela C, Estrela CRA, Barbin EL, et al. Mechanism of action of Sodium hypochlorite. Braz Dent J 2002;13(2):113-117. DOI: 10.1590/s010364402002000200007.

10. Mohammadi Z. Sodium hypochlorite in endodontics: an update review. Int Dent J 2008;58(6):329-341. DOI: 10.1111/j.1875-595x.2008.tb00354.x.

11. Kandaswamy D, Venkateshbabu N. Root canal irrigants. J Conserv Dent 2010;13(4):256-264. DOI: 10.4103/0972-0707.73378.

12. Clarkson RM, Podlich HM, Moule AJ. Influence of ethylenediaminetetraacetic acid on the active chlorine content of sodium hypochlorite solutions when mixed in various proportions. J Endod 2011;37(4):538-543. DOI: 10.1016/j.joen.2011.01.018.

13. Orhan EO, Irmak Ö, Hür D, et al. Does Para-chloroaniline really form after mixing sodium hypochlorite and chlorhexidine? J Endod 2016;42(3):455-459. DOI: 10.1016/j.joen.2015.12.024.

14. Wright PP, Kahler B, Walsh LJ. Alkaline sodium hypochlorite irrigant and its chemical interactions. Materials (Basel) 2017;10(10):1147. DOI: 10.3390/ma10101147.

15. Del Carpio-Perochena A, Bramante CM, Duarte MA, et al. Chelating and antibacterial properties of chitosan nanoparticles on dentin. Restor Dent Endod 2015;40(3):195-201. DOI: 10.5395/rde.2015.40.3.195. 